\title{
Hereditary Canine Spinal Muscular Atrophy: An Animal Model of Motor Neuron Disease
}

\author{
Linda C. Cork
}

\begin{abstract}
Motor neuron diseases selectively produce degeneration and death of motor neurons; the pathogenesis of these disorders and the specificity for this population of neurons are unknown. Hereditary Canine Spinal Muscular Atrophy produces a lower motor neuron disease which is clinically and pathologically similar to human motor neuron disease: motor neurons dysfunction and degenerate. The canine model provides an opportunity to investigate early stages of disease when there are viable motor neurons still present and might be responsive to a variety of therapeutic interventions. The canine disease, like the human disease, is inherited as an autosomal dominant. The extensive canine pedigree of more than 200 characterized individuals permits genetic analysis using syntenic linkage techniques which may identify a marker for the canine trait and provide insights into homologous regions for study in human kindreds.

RÉSUMÉ: L'amyotrophie spinale héréditaire du chien : un modèle animal de la maladie du neurone moteur. Les maladies du neurone moteur produisent la dégénérescence et la mort sélective des neurones moteurs; la pathogenèse de ces affections et la spécificité de l'atteinte de ces populations de neurones sont inconnues. L'amyotrophie spinale héréditaire du chien produit une maladie du neurone moteur de la corne antérieure qui est cliniquement et pathologiquement similaire à la maladie humaine du neurone motuer : une dysfonction et une dégénérescence des neurones moteurs. Le modèle canin fournit une occasion d'investiguer les stades précoces de la maladie, lorsque des neurones moteurs viables sont encore présents et pourraient répondre à des interventions thérapeutiques variées. La maladie du chien, comme la maladie chez l'humain, a une hérédité autosomale dominante. Un pedigree canin considérable, comprenant plus de 200 individus caractérisés, permet une analyse génétique utilisant des techniques de liaison synténique qui peuvent identifier un marquer de la maladie canine et indiquer des régions homologues pour l'étude de familles humaines.
\end{abstract}

Can. J. Neurol. Sci. 1991; 18: 432-434

Motor neuron diseases encompass the degenerative disorders which preferentially affect the upper and lower motor neurons and include amyotrophic lateral sclerosis and the spinal muscular atrophies. These diseases share common clinical features - progressive muscle weakness and atrophy of striated muscle leading to paralysis and fasciculations. Electromyography shows fibrillations, and muscle biopsies reveal denervation atrophy. In the adult onset diseases, and in some of the hereditary diseases of infancy and childhood, the disease progresses relentlessly until death ensues, usually as a result of the involvement of the muscles of respiration and swallowing. Some muscle groups are spared: the extraocular muscles and the vesicorectal sphincters. ${ }^{1-4}$

Autopsies show a consistent loss of motor neurons in the spinal cord, some motor nuclei, and motor cortex. In those patients dying early in the course of disease, the anterior horn contains large argyrophilic axonal swellings filled with neurofilaments, suggesting that alterations in the cytoskeleton may be an early feature of the disease process. ${ }^{5-7}$

Although the hereditary pattern of some motor neuron diseases is well established, many cases are thought to be sporadic. The phenotypic expression of the disease within individual families may be heterogeneous, i.e., juvenile spinal muscular atrophy and adult onset motor neuron disease may coexist within one family. ${ }^{8}$ As these disorders are scrutinized with a view to establishing genetic linkages and as more informative pedigrees are identified, the hereditary nature and mode of inheritance for more disorders may be identified.

Two genetic markers for motor neuron disease have been suggested. A genetic marker on chromosome 5 has been linked to both the benign and progressive forms of spinal muscular atrophy. ${ }^{9-11}$ Multipoint linkage analysis using restriction fragment length polymorphisms of families with amyotrophic lateral sclerosis suggests linkage to a region on chromosome 21 in some families. ${ }^{12}$ It seems likely that molecular genetic approaches will identify different genotypes of hereditary motor neuron disease among the various categories which have similar clinical presentations, and it is possible that the number of cases with a familial component will increase.

A motor neuron disease, Hereditary Canine Spinal Muscular Atrophy (HCSMA), has been identified in Brittany Spaniels ${ }^{13}$ and as in humans, it produces progressive weakness and atrophy of proximal muscle groups with fasciculations, fibrillations, and sparing of oculomotor muscles and vesicorectal sphincters. The clinical progression of muscle weakness in HCSMA is from

From the Division of Comparative Medicine, The Johns Hopkins University School of Medicine, Baltimore

Reprint requests to: Linda C. Cork, D.V.M., PhD., Division of Comparative Medicine, John Hopkins University School of Medicine, Baltimore, Maryland, U.S.A. 21205 
caudal to rostral and from proximal muscle groups to distal muscles. ${ }^{14}$

Breeding studies and pedigree analysis of autopsy confirmed cases, show the canine disease is inherited as an autosomal dominant. 15 Three patterns of disease have been recognized: accelerated, intermediate, and chronic. Pups with accelerated disease become weak between 6-8 weeks of age and progress rapidly to complete tetraparesis by $13-16$ weeks. Genetic analysis indicates that these pups are homozygous for the HCSMA trait. Intermediate and chronic phenotypes become weak during the first year of life, and the diagnosis is confirmed by muscle biopsy. Intermediate dogs progress to severe paresis over several years, but the course of disease in chronic dogs is benign. Chronically affected dogs have lived more than seven years with only mild clinical weakness, despite the fact that serial biopsies of proximal muscles have revealed denervation atrophy beginning in the first year of life and continuing throughout life. Both the intermediate and chronic phenotypes are heterozygous for HCSMA trait. 15

The pathologic features seen in HCSMA are reminiscent of those seen in human patients early in the course of disease, perhaps because affected dogs are typically killed humanely before muscles of respiration and swallowing are significantly compromised. Affected pups have pale chromatolytic neurons with greatly distended axonal internodes. The distended internodes contain maloriented swirls of neurofilaments, and the myelin sheath covering the distended internode may be attenuated or absent. A few motor neurons contain increased numbers of neurofilaments. In pups with longer survival and greater deficits, there is clear evidence of neuronophagia. ${ }^{16}$ In dogs with intermediate disease, axonal swellings are fewer in number, but axons may be enlarged diffusely along the length of the axon obliterating the constriction normally present at the node of Ranvier.

The nature of the dysfunction of the motor neurons in HCSMA has been examined using morphometric, immunocytochemical, and molecular biologic methods. In accelerated and intermediate phenotypes, the rate of transport of the low molecular weight neurofilament peptide and tubulin were decreased to approximately half that of control values. ${ }^{17}$ It is not clear whether this is a primary defect, but subsequent studies suggest that the decrease in the rate of transport probably reflects a decrease in synthesis of neuronal cytoskeletal proteins by ventral horn neurons.

The ventral horn neurons in the cervical enlargement of HCSMA dogs with early intermediate disease were smaller than in controls, and affected dogs had more than $25 \%$ more neurons than age-matched control dogs. In adjacent sections, an antibody against choline acetyl transferase (ChAT) was used to immunocytochemically identify putative cholinergic neurons, but the numbers of ChAT immunoreactive neurons did not differ between HCSMA and controls: however, the ChAT immunoreactive neurons in HCSMA were smaller than in controls. In concert, these observations suggest that in HCSMA some putative cholinergic neurons do not express their appropriate transmitter phenotype. Moreover, it seems likely that neurons in HCSMA never attain normal size and some may fail to undergo the normal period of "cell death" during development. ${ }^{18}$

Morphometric studies of ventral rootlets in HCSMA were consonant with these observations. When the caliber of axons in
HCSMA accelerated pups and intermediate dogs was compared with controls, the axonal diameter and area of roots in HCSMA were smaller than in controls suggesting that axons in HCSMA fail to achieve normal caliber. The decrease in circularity of the axons and the alteration in the relationship between the thickness of the myelin sheath and the caliber of the axon, indicate that in intermediate dogs, not only was the growth of axons arrested, but that these hypotrophic axons subsequently atrophy. These alterations in axonal caliber, shape, and myelin relationship were greatest in large caliber axons. There was no evidence in these roots of Wallerian degeneration i.e., Bungner bands or phagocytosis. 19

Preliminary data from in situ hybridization studies of pups with early accelerated disease suggest that the decrease in neuronal (and axonal) size observed in HCSMA may be related to a decrease in the expression of the low molecular weight neurofilament mRNA, but other cytoskeletal proteins may not be as affected (N. Muma and L.C. Cork, unpublished observations). If this proves to be the case, the canine disease may provide a interesting model in which to examine the regulation of different components of the cytoskeleton.

Recently, Plaitakis has hypothesized that there is a generalized defect in the metabolism of excitotoxic amino acids in motor neurons in amyotrophic lateral sclerosis ${ }^{20}$ resulting in a decrease in $\mathrm{N}$-acetylaspartate (NAA), $\mathrm{N}$-acetyl-aspartyl glutamate (NAAG), glutamate, and aspartate. Alterations in the concentration of aspartate and glutamate in the cerebrospinal fluid and plasma of patients with amyotrophic lateral sclerosis have been documented leading to the hypothesis that death of motor neurons in ALS may be related to inappropriate regulation of the excitotoxic amino acids. ${ }^{21,23}$ Preliminary data from pups early in accelerated HCSMA suggest that levels of NAA, NAAG, glutamate and aspartate are decreased in the spinal cord of affected dogs but not in motor or occipital cortices in which clinical or morphological evidence of disease has not been detected. (Guo Tsai, L.C. Cork, J. Coyle unpublished observations). It is not yet clear whether this is a primary change in motor neuron biology or a secondary effect of the disease process.

The availability of the HCSMA model provides the opportunity to ask important scientific questions about the structure and biological properties of motor neurons in a degenerative disease and how these are regulated. For example, the axotomy model provides a useful model in which to examine how a neuron responds acutely to injury. Following axotomy, nerve growth factor (NGF) has been shown to "rescue" central cholinergic neurons, ${ }^{24}$ and NGF receptor mRNA is developmentally regulated and increases after axotomy. ${ }^{25}$ Does a similar situation pertain in a progressive degenerative disease such as ALS or HCSMA? Could therapeutic intervention with NGF, or another appropriate growth factor, prevent or retard the degeneration of neurons in HCSMA?

The canine disease also offers several advantages which can be scientifically exploited in genetic studies: the extended HCSMA kindred of more than 200 characterized members, the possibility to make selective matings, and the availability of large amounts of tissue for analysis with molecular biologic strategies. In concert, these features of HCSMA provide a unique opportunity to examine putative genetic markers for motor neuron disease and provide a resource for understanding the regulation 
of the biological properties of motor neurons.At present, we are examining restriction fragment length polymorphism in the HCSMA kindred to identify genes whose linkage is known to be phylogenetically conserved between human and mice, i.e., syntenic genes. By using genes known to be syntenic in dogs and humans which identify homologous regions of various human chromosomes, we can ask whether any of these human chromosomal markers/syntenic genes are linked to the HCSMA trait. Moreover, using currently available markers, we can ask whether any of the markers associated with human spinal muscular atrophy or ALS are linked to the HCSMA trait. The size of the HCSMA kindred, the possibility of analyzing multiple generations with sibships as large as 23 members, make this model a very powerful tool for genetic analysis.

In conclusion, the canine model of motor neuron disease, HCSMA, provides an opportunity to investigate the biology of motor neurons and the features which make them vulnerable/resistant to injury at both the clinical and molecular levels.

\section{ACKNOWLEDGEMENTS}

I thank Drs. George Sack, Donald Price and Guo Tsai for helpful discussions. Supported in part by PHS grants NS10580 and RR00130 from the National Institutes of Health.

\section{REFERENCES}

1. Rowland LP. Motor neuron diseases and amyotrophic lateral sclerosis. TINS 1984; 7: 110-112.

2. Tandan R, Bradley WG. Amyotrophic lateral sclerosis: Part 2, Etiopathogenesis. Ann Neurol 1985; 18: 419-431.

3. Harding $A E$. Inherited neuronal atrophy and degeneration predominantly of lower motor neurons. In: Dyck PJ, Thomas PK, Lambert EH, et al., eds. Peripheral Neuropathy. Philadelphia: W.B. Saunders, 1984 ; 1538-1556.

4. Mulder DW. Motor neuron disease. In: Dyck PJ, Thomas PK, Lambert EH, et al, eds. Peripheral Neuropathy. Philadelphia: W.B. Saunders, 1984; 1525-1536.

5. Hirano A. Progress in the pathology of motor neuron diseases. In: Zimmerman HM ed. Progress in Neuropathology. New York: Grune \& Stratton, 1973; 181-215.

6. Carpenter S. Proximal axonal enlargement in motor neuron disease. Neurology 1968; 18: 841-851.

7. Delisle MB, Carpenter S. Neurofibrillary axonal swellings and amyotrophic lateral sclerosis. J Neurol Sci 1984; 63: 241-250.

8. Appelbaum J, Roos RP Salazar-Grueso EF, et al. Intrafamilial heterogeneity of motor neuron diseases. Ann Neurol 1990; 28: 268 (Abstract).
9. Brzustowicz LM, Lehner T, Castillia L, et al. Genetic mapping of chronic childhood-onset spinal muscular atrophy to chromosome 5q11.2-13.3. Nature 1990; 344: 540-541.

10. Melki J, Abdelhak S, Sheth $P$, et al. Gene for chronic proximal spinal muscular atrophies maps to chromosome $5 q$. Nature 344: 767-768.

11. Gilliam TC, Brzustowicz LM, Castillia LH, et al. Genetic homogenity between acute and chronic forms of spinal muscular atrophy. Nature 1990; 345: 823-825.

12. Siddique T, Pericak-Vance MA, Roos RP, et al. Multipoint linkage analysis of chromosome 21 restriction fragment length polymorphism markers to familial amyotrophic lateral sclerosis. Ann Neurol 1990; 28: 269 (Abstract).

13. Cork LC, Griffin JW, Munnell JF, et al. Hereditary canine spinal muscular atrophy. J Neuropathol Exp Neurol 1979; 38: 209-221.

14. Lorenz MD, Cork LC, Griffin JW, et al. Hereditary spinal muscular atrophy in Brittany Spaniels: clinical manifestations. JAVMA 1979; 175: 833-839.

15. Sack Jr GH, Cork LC, Morris JM, et al. Autosomal dominant inheritance of hereditary canine spinal muscular atrophy. Ann Neurol 1984; 15: 369-373.

16. Cork LC, Griffin JW, Choy C, et al. Pathology of motor neurons in accelerated hereditary canine spinal muscular atrophy. Lab Invest 1982; 46: 89-99.

17. Griffin JW, Cork LC, Adams RJ, et al. Axonal transport in hereditary canine spinal muscular atrophy (HCSMA). J Neuropath Exp Neurol 1982; 41: 370.

18. Cork LC, Altschuler RJ, Bruha PJ, et al. Changes in neuronal size and neurotransmitter markers in hereditary canine spinal muscular atrophy., Lab Invest 1989; 61: 69-76.

19. Cork LC, Struble G, Gold BG, et al. Changes in the size of motor axons in hereditary canine spinal muscular atrophy. Lab Invest $1989 ; 61: 333-342$.

20. Plaitakis A. Glutamate dysfunction and selective motor neuron degeneration in amyotrophic lateral sclerosis: an hypothesis. Ann Neurol 1990; 28: 3-8.

21. Perry TL, Krieger C, Hansen S, et al. Amyotrophic lateral sclerosis: amino acid levels in plasma and cerebrospinal fluid. Ann Neurol 1990; 28: 12-17.

22. Rothstein JD, Tsai G, Kuncl RW. Abnormal excitatory amino acid metabolism in amyotrophic lateral sclerosis. Ann Neurol 1990; 28: $18-25$

23. Perry TL, Hansen S, Jones K. Brain glutamate deficiency in amyotrophic lateral sclerosis. Neurology 1987; 37: 1845-1848.

24. Hefti F. Nerve growth factor promotes survival of septal cholinergic neurons after fimbrial transections. J Neurosci 1986; 6: 21552162.

25. Ernfors $\mathrm{P}$ Henschen A, Olson L, et al. Expression of nerve growth factor receptor mRNA is developmentally regulated and increased after axotomy in rat spinal cord motoneurons. Neuron 1989; 2: 1605-1613. 